\title{
Voluntary Ingestion of a Cola Nut Stuck into the Esophagus: An Unusual Foreign Body (FB)
}

\author{
Ismaïl Lawani1, Dansou Gaspard Gbéssi2², Aboudou Raimi Kpossou ${ }^{3}$, \\ Yacoubou Imorou Souaïbou ${ }^{2}$, Freddy H. R. Gnangnon ${ }^{2}$, Francis Moïse Dossou ${ }^{1}$, \\ Delphin Kuassi Mehinto ${ }^{4}$, Jean-Léon Olory-Togbé ${ }^{2}$ \\ ${ }^{1}$ General Surgery Unit, CHUD/OP Porto-Novo, Cotonou, Bénin \\ ${ }^{2}$ Visceral Surgery Unit "A", CNHU-HKM, Cotonou, Bénin \\ ${ }^{3}$ Hepato-Gastroenterology Unit, CNHU-HKM, Cotonou, Bénin \\ ${ }^{4}$ Visceral Surgery Unit "B", CNHU-HKM, Cotonou, Bénin \\ Email: "gbessi1@yahoo.fr
}

Received 10 April 2016; accepted 14 May 2016; published 17 May 2016

Copyright (C) 2016 by authors and Scientific Research Publishing Inc.

This work is licensed under the Creative Commons Attribution International License (CC BY). http://creativecommons.org/licenses/by/4.0/

(c) (i) Open Access

\section{Abstract}

The cola nut (Cola nitida), is a rare foreign body. Its voluntary ingestion, for ritual practices, is a situation of exceptional occurrence, and jamming it in the esophagus is a therapeutic emergency. Here, we report the case of an adult patient, with a cola nut measuring $3 \mathrm{~cm}$ in diameter swallowed for a ritual purpose, jammed at the bottom of his esophagus. A surgical extraction was performed by gastrostomy after a failed attempt of endoscopic extraction. There ensued a complication of a left-esophageal fistula. The various aspects of this case are analyzed in the light of the literature review.

\section{Keywords}

Foreign Body, Esophagus, Cola Nut, Gastrostomy

\section{Introduction}

Esophageal ingested foreign bodies are a relatively frequent emergency, which occur more often accidentally than voluntarily [1]. The majority of foreign bodies that reach the gastro intestinal tract, true foreign objects and food bolus impactions, will pass spontaneously [1]. Their management is multidisciplinary [1] [2]; although

\footnotetext{
*Corresponding author.
} and Olory-Togbé, J.-L. (2016) Voluntary Ingestion of a Cola Nut Stuck into the Esophagus: An Unusual Foreign Body (FB). Surgical Science, 7, 239-243. http://dx.doi.org/10.4236/ss.2016.75034 
deaths caused by foreign body ingestion have rarely been reported, mortality rates have been extremely low [1]. Their nature varies, with some rarer and more unusual than others [3]-[6]. The cola nut or Cola nitida is an exceptional foreign body reported by some authors among whom Okeowo in 1985 [7] and Akenroye in 2012 [8]. We report a case of cola nuts voluntarily ingested in a ritual purpose and which was jammed in the lower esophagus, requiring a surgical extraction.

\section{Case Description}

It is about a patient of 42, a laboratory technician, who was admitted, 20 hours after he had voluntarily ingested a cola nut, in the frame of a ritual. According to the patient, the cola nut, after it had been ingested, should have come out intact through the anus and be used to make a love potion. He said he had felt, immediately after the ingestion, an odynophagia and a jamming of the cola nut in his cervical esophagus. A few hours later, he started feeling retro sternal pain, showing signs of hypersalivation and total intermittent dysphagia. The patient had no past history of esophageal-gastric or psychiatric pathology. Upon examination, the patient appeared anxious, in good condition, with a salivary stasis in the oropharynx. His front and profile chest X-ray performed with soft rays were normal. It was then decided on an observation in the hope of a spontaneous elimination of the cola nut. The absence of elimination motivated, on the 3rd day of hospitalization, the performance of an esophageal endoscopy which found the cola nut (Figure 1(a)) jammed in the esophagus at about $23 \mathrm{~cm}$ from the dental arches. All the attempts at removing it by the mouth or pushing it into the stomach failed. The day following the endoscopy, a surgical extraction of the cola nut was performed through a gastrostomy (Figure 1(b)). It measured $3 \mathrm{~cm}$ in diameter (Figure 1(c)). While an assistant was pushing the cola nut by the upper route with a CH34 Savary candle, the surgeon, with a gastrostomy, extracted the cola nut by pushing his finger upward in the esophagus. At the end of the surgery, the palpation of the lower esophagus did not show any clinically detectable pathology that may have lead to the jamming of the cola nut. However, on the other hand, an iatrogenic perforation of the esophagus was suspected. His esophagus was filled with methylene blue by the upper route. This resulted into a bluish coloration of the peri-esophageal compress, thus confirming an esophageal breach. It occurred in the lower part, located at about $8 \mathrm{~cm}$ from the esophageal hiatus. All attempts at suturing it was vain. A nasogastric tube was left in place. On the fourth postoperative day, an accidental fall of the nasogastric tube was observed. To avoid wrong way swallowing, it was decided not to replace the tube. Complications ensued with a bilateral pneumothorax and pleurisy (Figure 2(a)), a mediastinitis and a left esopleural fistula (Figure 2(b)). A triple treatment consisting of an antibiotic therapy, a bilateral pleural drainage (Figure 2(c)), and an oxygen therapy was used. The esophageal fistula had dried up by the 35th postoperative day (39th day of hospitalization). Feeding resumed without dysphagia after a leakage checking of the esophagus through a gastroesophageal transit (Figure 2(d)) and the patient returned to his home after 44 days of hospitalization. Patient has been reviewed after 3 months and one year. He doesen’t complain any dysphagia or other esophageal symptom.
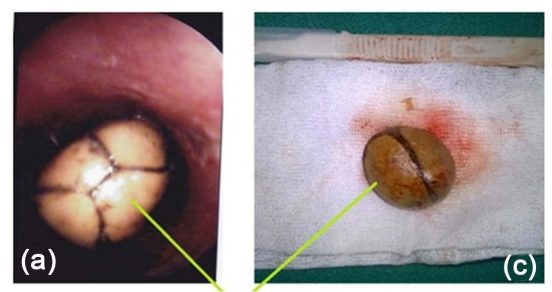

cola nut

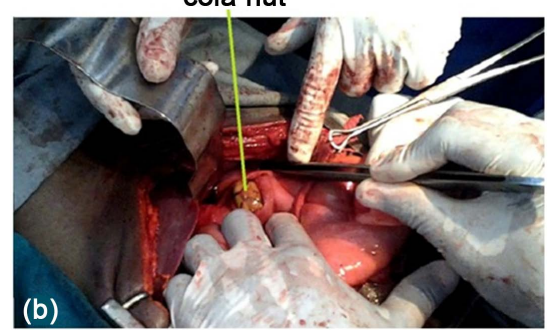

Figure 1. (a) Endoscopic view of the cola nut blocked in the esophagus; (b) Intraoperative view of the cola nut; (c) Whole cola nut after extraction. 

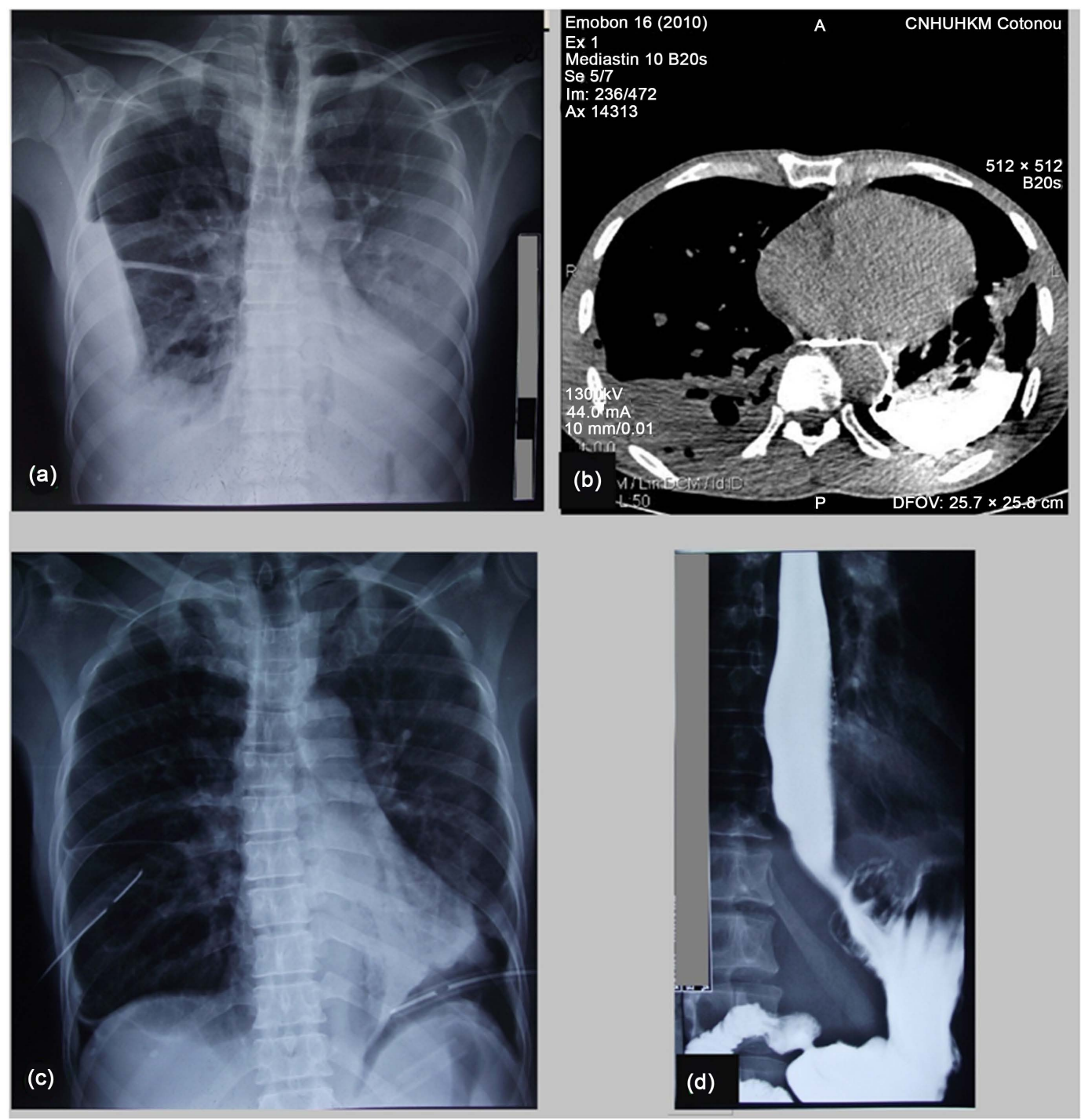

Figure 2. (a) Pneumothorax and bilateral pleurisy; (b) Left esopleural fistula; (c) Bilateral thoracic drainage; (d) Leakage checking of the esophagus before feeding is resumed.

\section{Discussion}

Ingested foreign bodies are regularly met. Most of them go spontaneously down through the digestive tract, $10 \%$ - $20 \%$ require nonoperative care, and only $1 \%$ will require surgical treatment [1]. The various anatomical strictures of the esophagus are potential points of foreign bodies impaction [9]. Foreign bodies jammed in the esophagus are an emergency which can cause significant morbidity [10]. Many factors favoring impaction have been described: esophageal strictures, esophagitis, Schatzki ring, esophageal diverticula, hiatal hernia, achalasia, esophageal atresia, previous esophageal surgery [10]. Our patient had none of these factors. The only factor that may account for the blocking of the cola nut is its size. Indeed Duncan [9] and Triadafilopoulos [10] specify that the objects that exceed $2 \mathrm{~cm}$ in diameter cannot easily go through a normal adult esophagus. However, the nut ingested by our patient measures $3 \mathrm{~cm}$ in diameter. The deliberate ingestion of foreign bodies in adults is most often seen with patients presenting psychiatric disorders, prisoners, and drug traffickers [10]. Our patient had no psychiatric disorder. The purpose for the ingestion was ritual: making a love potion. This purpose was exceptionally reported. The two cases that we found on PubMed [7] [8] were observed in Nigeria, a country of West Africa, just like Benin. According to Akoegninou [11], the Cola nitida is a plant originating from West Africa. Kouame [12] specifies that it is cultivated from Senegal to Nigeria, while Starin [13] underlines its importance 
and use in various aspects of life with West African communities. As for dysphagia, it is a classic symptom of esophageal obstruction. When the patient specifies the characteristics of the FB on admission, this allows to quickly plan the appropriate support. But when it comes to unusual objects like a cola nut or a calabash [8], the patient may feel ashamed and then deny having ingested any object until the latter is evidenced. In our case, the patient stated the nature of the FB and the purpose of its ingestion. The localization of the FB in the digestive tract is desirable before attempting extraction [10]. Radiography in our patient showed no FB. This is due to the radiolucent nature of the cola nut, because of its essentially organic composition, as previously detailed by Dewole [14]. Some non-surgical methods such as the intravenous administration of glucagon and ingesting oily substances have been proposed to facilitate the spontaneous descent of esophageal FBs towards the stomach [10]. In case of failure, the flexible fiberoptic esophagoscopy with sedation or general anesthesia is the preferred method to extract the FB through the mouth or push it in the stomach with a success rate of $90 \%$, and less than $5 \%$ complications [15] [16]. It is necessary, before starting such a procedure, to have many accessories [10] available to the endoscopist. The endoscopic fragmentation of the cola nut could have enabled its extraction [10], this method was successfully used in a similar case described by Akenroye [8]. Surgery is the last therapeutic alternative [1] [10]. The choice of the route first depends on the seat of the FB impaction in the esophagus. Esophagotomy remains the commonest way used. However, in case of prolonged impaction of the FB as was the case in our patient, there is a peri-esophageal inflammation which makes the intraoperative localization of the FB difficult, and therefore the seat of the esophagotomy uncertain. Saha [2] suggests an intraoperative esophagoscopy to locate the seat of the impaction by transillumination and then guide the esophagotomy. Because of the low seat of the FB, an extraction by gastrostomy was performed. Many complications including esophageal perforation are described with cases of FB ingestion [10]. The duration of impaction and the size of the FB are the two main independent risk factors associated with the development of these complications [10]. Sharpness or pointedness of ingested objects, and the ischemia caused by the prolonged compression of objects with a foam texture are the two commonest mechanisms which occur regarding perforations [17]. In our patient, it was an iatrogenic complication, given the absence of signs suggestive of perforation before surgery. The non-surgical treatment of that perforation in our patient resulted in complications whose management turned out to be successful. The conservative treatment of the perforation was based on Altorjay's eligibility criteria as quoted by Rosiere [18]. Among the assessable intraoperative criteria, two were fulfilled and accounted for the conservative attitude, especially as all the attempts at identifying the location of the puncture had failed.

\section{Conclusion}

The voluntary ingestion of a cola nut for ritual purposes led to a blockage in the esophagus. The surgical extraction resulted in an esophageal wound with well advanced mediastinitis and pleural complications. The size of the FB should have been considered as its ingestion is essential for a ritual.

\section{Acknowledgements}

Many thanks to Dr AZON Fortuné Sènakpon, for English translation.

\section{References}

[1] Eisen, G.M., Baron, T.H., Dominitz, J.A., Faigel, D.O., Goldstein, J.L., Johanson, J.F., et al. (2002) Guideline for the Management of Ingested Foreign Bodies. Gastrointestinal Endoscopy, 55, 802-806. http://dx.doi.org/10.1016/S0016-5107(02)70407-0

[2] Saha, S. and Bose, A. (2011) Perils of Prolonged Impaction of Oesophageal Foreign Bodies. ISRN Surgery, 2011, Article ID: 621682. http://dx.doi.org/10.5402/2011/621682

[3] El Marini, H., El Belloute, S., Benelbarhdadi, I., Essamri, W., Ajana, F.Z., Afifi, R., et al. (2001) Les variétés des corps étrangers ingérés dans notre pratique quotidienne. Acta Endoscopica, 41, 123-128. http://dx.doi.org/10.1007/s10190-011-0160-1

[4] Mallick, F.R., Sahota, R.S., Elloy, M.D. and Conboy, P.J. (2014) A Rare Case of Foreign Body Impaction Requiring Oesophagotomy. Annals of the Royal College of Surgeons of England, 96, e11-e13. http://dx.doi.org/10.1308/003588414x13814021678998

[5] Rathore, P.K., Raj, A., Sayal, A., Meher, R., Gupta, B. and Girhotra, M. (2009) Prolonged Foreign Body Impaction in the Oesophagus. Singapore Medical Journal, 50, e53-e54. 
[6] Sondhi, V., Patnaik, S.K. and Khullar, A. (2012) Procedural Sedation Associated Displacement of Sharp Oesophageal Foreign Body. BMJ Case Reports. http://dx.doi.org/10.1136/bcr.11.2011.5235

[7] Okeowo, P.A. (1985) Foreign Bodies in the Pharynx and Oesophagus: A Ten Year Review of Patients Seen in Lagos. Nigerian Quarterly Journal of Hospital Medicine, 3, 46-50.

[8] Akenroye, M.I. and Osukoya, A.T. (2012) Uncommon Undeclared Oesophageal Foreign Bodies. Nigerian Journal of Clinical Practice, 15, 244-246. http://dx.doi.org/10.4103/1119-3077.97339

[9] Duncan, M. and Wong, R.K.H. (2003) Esophageal Emergencies: Things That Will Wake You from a Sound Sleep. Gastroenterology Clinics of North America, 32, 1035-1052. http://dx.doi.org/10.1016/S0889-8553(03)00087-6

[10] Triadafilopoulos, G., Roorda, A. and Akiyama, J. (2013) Update on Foreign Bodies in the Esophagus: Diagnosis and Management. Current Gastroenterology Reports, 15, 317-322. http://dx.doi.org/10.1007/s11894-013-0317-5

[11] Akoegninou, A., van der Burg, W.J. and van der Maesen, L.J.G. (2006) Flore analytique du Bénin. In: Adjakidjè, V., Essou, J.P., Sinsin, B. and Yédomonhan, H., Eds., Wagening University Papers 06.2, Backhus Publishers.

[12] Kouame, C. and Sacande, M. (2006) Cola nitida (vent.) Schott \& Endl. Seed Leaflet, 111.

[13] Starin, D. (2013) Kola Nut: So Much More than Just a Nut. Journal of the Royal Society of Medicine, 106, $510-512$. http://dx.doi.org/10.1177/0141076813507708

[14] Dewole, E.A., Dewumi, D.F.A., Alabi, J.Y.T. and Adegoke, A. (2013) Proximate and Phytochemical of Cola nitida Ant Cola Acuminate. Pakistan Journal of Biological Sciences, 16, 1593-1596. http://dx.doi.org/10.3923/pjbs.2013.1593.1596

[15] Chen, T., Wu, H.F., Shi, Q., Zhou, P.H., Chen, S.Y., Xu, M.D., et al. (2013) Endoscopic Management of Impacted Esophageal Foreign Bodies. Diseases of the Esophagus, 26, 799-806. http://dx.doi.org/10.1111/j.1442-2050.2012.01401.X

[16] Wu, W.T., Chiu, C.T., Kuo, C.J., Lin, C.J., Chu, Y.Y., Tsou, Y.K., et al. (2011) Endoscopic Management of Suspected Esophageal Foreign Body in Adults. Diseases of the Esophagus, 24, 131-137. http://dx.doi.org/10.1111/j.1442-2050.2010.01116.x

[17] Balasubramaniam, S.K., Bray, D., Black, M.I., Salama, N.Y. and Mitchell, D.B. (2008) A Review of the Current Management of Impacted Foreign Bodies in the Oesophagus in Adults. European Archives of Oto-Rhino-Laryngology, 265, 951-956. http://dx.doi.org/10.1007/s00405-007-0575-7

[18] Rosière, A., Michel, L., Scavée, V., Mulier, S. and Khoury, A. (2004) Traitement des perforations œsophagiennes. Encycl Med Chir; (Elsevier SAS, Paris), Technique Chirurgicale, 40-220. http://dx.doi.org/10.1016/j.emchi.2004.02.002 